\title{
RSV DOWNREGULATES IL-21/IL-21R ON TFH CELLS VIA PD-L1 INDUCTION IN APCS IMPAIRING PROTECTIVE HUMORAL RESPONSES
}

Rodrigo Benedetti Gassen 1.2; Tiago Fazolo 1.2; Deise Nascimento de Freitas ${ }^{2}$, Thiago J. Borges ${ }^{1}$; Fábio Maito ${ }^{3}$; Daniel A. G. Bueno Mendes $^{5}$, André Báfica ${ }^{5}$, Luiz Carlos Rodrigues $\mathrm{Jr}^{4}$, Ana Paula Duarte de Souza ${ }^{2}$; Cristina Bonorino ${ }^{1}$.

1. Laboratório de Imunologia Celular e Molecular, Pontifícia Universidade Católica do Rio Grande do Sul;

2. Laboratório de Imunologia Clínica e Experimental, Pontifícia Universidade Católica do Rio Grande do Sul;

3. Laboratório de Histologia, Faculdade de Odontologia, Pontifícia Universidade Católica do Rio Grande do Sul;

4. Laboratório de Imunologia, Universidade Federal de Ciência da Saúde de Porto Alegre;

5. Laboratório de Imunobiologia, Universidade Federal de Santa Catarina, Florianópolis, Santa Catarina.

\section{Corresponding Author:}

Cristina Bonorino

Av. Ipiranga, 6690. 2nd floor, Labs 6-8. - São Lucas Hospital - IPB, PUCRS

Porto Alegre, RS - Brazil - 90610-900

Phone: (+55) 51-3320.3000 ext. 2725

Fax: (+55) 51-3320.3312

E-mail: cbonorino@pucrs.br 


\section{ABSTRACT}

Respiratory syncytial virus (RSV) is the major cause of hospitalization for children under two years of age. RSV vaccines are currently unavailable, and children suffering from multiple reinfections by the same viral strain, fail to develop protective memory responses. Follicular helper T (TFH) cells specialize in providing B cell help to antibody production and affinity maturation, mainly via IL-21 secretion. Although RSV-specific antibodies can be detected upon infection, how they are generated and their relevance against disease protection has not been fully examined. Here, we observed that RSV expands a functionally impaired murine TFH cell population in vitro and vivo, with downregulated IL-21R expression and IL-21 production. IL-21 treatment of RSVinfected mice, however, increased TFH cells frequency, enhanced the germinal center reaction and improved protective humoral immune responses by increasing viral protein F specific antibody avidity and neutralization capacity. In vivo, it protected from RSV infection, decreasing lung inflammation. Passive immunization with purified IgG from IL-21 treated RSV-infected mice protected against RSV infection. Both viable and UV-inactivated RSV induced PD-L1 expression on B cells and DCs, however, only in DCs a direct effect of RSV was detected. Blocking PD-L1 during infection recovered IL-21R expression in TFH and B cells and increased secretion of IL-21 by TFH cells in a DC-dependent manner. Our results unveil a novel pathway by which RSV affects TFH cells activity, reducing levels of IL-21 and its receptor, by increasing PD-L1 expression on APCs. These results highlight the PD-L1/IL-21 axis importance for the generation of protective responses to RSV infection.

Key words: respiratory syncytial virus; follicular helper T cells; IL-21; germinal center reaction

Abstract word count: 253 


\section{INTRODUCTION}

Respiratory syncytial virus (RSV) is the leading cause of lower respiratory tract infection in infants, responsible for about three million hospitalizations and 66,000 deaths every year in children under two years of age (1). RSV-infected infants develop upper respiratory tract symptoms, often progressing to bronchiolitis and/or pneumonia, and even respiratory failure, which frequently needs mechanical ventilation and intensive care unit therapy (2). There is no effective vaccine available against RSV, and passive immunization with monoclonal antibodies is used only in high risk infants, in which RSV infection can be deadly. However, it is not only in premature children that RSV infection may be problematic or deadly; infants, elderly and pregnant women are also target populations (3), reinforcing the need for development of an effective vaccine .

In humans, neutralizing RSV-specifics antibodies are formed in upper respiratory tract, however, re-infection with the same RSV strain is frequent in healthy, immune competent individuals $(4,5)$. The protective relevance of serum antibody levels remains unclear $(6,7)$. Serum antibody response was loosely correlated with protection; however, there was a correlation of nasal preexisting RSV-specific humoral response with resistance to re-infection (8). Other studies have correlated the presence of serum high avidity RSV-specific IgG with protection (9); although these antibodies have a short life in children (10) and adults (11). Nevertheless, RSV morbidity and mortality are mainly associated with 2-4 months of age infants when titers of maternal antibodies are decreasing and have not yet been replaced by an endogenous antibody responses (12). In mice, the RSV antibody response induced by formalin-inactivated RSV (FIRSV) is non-protective (13). Formalin inactivation results in conformational changes of 
the RSV fusion protein (14), which is required for the generation of effective neutralizing antibody responses (15). Moreover, antibodies induced by FI-RSV are low affinity due to poor toll-like receptor (TLR) stimulation (16).

Effective B cells responses require help from follicular helper T (TFH) cells. TFH cells are predominantly found in germinal centers (GC) of secondary lymphoid organs (1719) and produce high levels of IL-21. This cytokine is known to increase the affinity of antibodies and induce immunoglobulin class switching $(20,21)$. IL-21 acts on naive B cells in conjunction with co-stimulatory signals which drive differentiation of either GC B cells or plasma cells (22). The specific provision of TFH cell-derived helper signals to GC B cells is proposed to be the major driver of antibody affinity maturation $(23,24)$. Therefore, we hypothesized that RSV modulates TFH cells, preventing B cell help, targeting humoral immune response efficiency.

By employing a murine model of RSV infection, our results unravel an immunological mechanism by which RSV modulates TFH cells and GC reactions. We found that RSV can induce PD-L1 (Programed Death-ligand 1) in dendritic cells (DCs) and B cells, decreasing B and TFH cells functions. This correlated with a decreased ability of TFH cells to produce IL-21 and downregulation of IL-21R, leading to low avidity RSVspecific humoral immune response. Treatment with recombinant IL-21 reduced RSVmediated impairment of GC and TFH cell functions as well as improved animal survival. Our results underline the importance of the PD-1/PD-L1 pathway and IL-21 adjuvant activity in the generation of effective anti-RSV protective antibody responses. 


\section{METHODS}

\section{Viruses and Cells}

Vero cells (ATCC CCL81) were cultured in Dulbeccol's modified Eagle's medium (DMEM, Gibco-BRL) containing 10\% fetal calf serum (FCS, Gibco-BRL) and gentamicin $\left(0.08 \mathrm{mg} / \mathrm{ml}\right.$, NOVAFARMA), maintained at $37^{\circ} \mathrm{C}$ with $5 \%$ of $\mathrm{CO}_{2}$ and used to propagate RSV A2 strain and HSV-1 KOS strain. Viral plaque-forming units (PFU) were identified using an RSV F protein-specific antibody (Millipore, Billerica, MA, USA). Lytic plaques assay was used to calculate PFU of HSV-1. Inactivation of the viruses was performed at UV light for $30 \mathrm{~min}$, at room temperature.

\section{Animals}

Female BALB/c mice ranging from 6 to 8 weeks old were purchased from the Biological Center of Experimental Models (CEMBE) of PUCRS. Mice were housed in CEMBE facility with water and food ad libitum. All animal procedures were performed in accordance with the guidelines of the Federation of Brazilian Societies for Experimental Biology and approved by the Ethics Committee for the Use of Animals of PUCRS (CEUA-PUCRS; protocol number \#13/00341).

\section{Infection and treatment}

For in vitro infection, splenocytes were isolated after lysis of red blood cells. Cells were seeded at $5 \times 10^{5}$ cells per well in a 96 well-plate and were stimulated either with $10^{2}$ $\mathrm{PFU} / \mathrm{ml}$ of $\mathrm{HSV}-1$ or RSV or the same virus inactivated by UV for $30 \mathrm{~min}$. As negative controls, uninfected Vero cells were used and processed similarly to RSV infected cells. Alternatively, cells were treated with $0.5 \mu \mathrm{g}$ of anti-PD-L1 antibody (clone MHI5, eBioscience) or control IgG (BioXcell) 1 hour before infection. The supernatant was 
collected at 12, 24, 48, 72 and 96 hours post-infection for analysis. After four days, cells were labeled with specific antibodies and analyzed by flow cytometry.

For sorting, splenocytes were isolated after lysis of red blood cells and stained with specific antibodies for DCs (CD11C ${ }^{+}$CD19-), B cells (CD19+CD11c) and TFH cells $\left(\mathrm{CD}^{+}{ }^{+} \mathrm{CXCR} 5^{+}\right)$. Cells were co-cultured $\left(5 \times 10^{3} \mathrm{DCs}, 3 \times 10^{4} \mathrm{TFH}\right.$ cells or $5 \times 10^{4} \mathrm{~B}$ cell per well) in different combinations, and later infected with $10^{2} \mathrm{PFU} / \mathrm{ml}$ of RSV for 4 days. Alternatively, cells were treated with $0.5 \mu \mathrm{g}$ of anti-PD-L1 antibody (clone MHI5, eBioscience) or IgG (BioXcell), 1 hour before infection, and analyzed for IL-21R and PD-L1 expression.

For in vivo infection, mice were divided into 5 groups: two groups were infected intranasally with $10^{7} \mathrm{PFU}$ of $\mathrm{RSV}$, and one of this group received subcutaneous treatment with $0.5 \mu \mathrm{g}$ of recombinant IL-21 (eBioscience) diluted in PBS. Two groups received PBS intranasally, and one of this group received treatment with recombinant IL-21 subcutaneously. And the last group was infected with $10^{7} \mathrm{PFU}$ of HSV-1 via intraperitoneal. IL-21 was administered on days: 4, 8, 14 and 18 post-infection. The blood collection occurred on days $0,4,8,14,18$ and 21 post-infection. Mice were euthanized at day 21 post-infection and spleens and lungs were harvested for further analysis.

\section{ELISA}

IL-21 concentration in supernatant and serum was determined by capture ELISA (R\&D Systems), according to manufacturer's instructions.

For the quantification of IgG RSV specific antibodies on mice serum, 96-well plates were sensitized overnight with RSV F protein (Sino Biological Inc.), blocked for 1 hour with blotto (5\% milk, $0.05 \%$ tween in PBS $1 \mathrm{X}$ buffer) and serum was added in dilutions 
of $1 / 10,1 / 100,1 / 500,1 / 1000,1 / 5000$ and incubated for 2 hours at room temperature. Rabbit anti-mouse antibody HRP-conjugated (Invitrogen) and TMB (Life Technologies) was used to development. Plates were read at 450nm in EZ Read 400 Microplate reader (Biochrom).

ELISA to measure the avidity of anti-RSV antibody was conducted in the same manner, however the plate was washed with a $6 \mathrm{M}$ Urea solution. The results were expressed as an Avidity Index (Al), which was calculated as previously described by Freitas et al (9). The avidity of RSV-specific total IgG was classified according to values that had been predetermined arbitrarily defined as low $(<50 \%)$, intermediate $(50-70 \%)$, or high $(>70 \%)$

\section{Neutralization assay}

Antibody neutralization capacity assay was performed as previously described by Zielinska et al (26), with modifications. Four-fold serial dilutions from 1:10 to $1: 10240$ were prepared in virus diluent (DMEM 0\% FCS and $1 \%$ gentamicin $(0.08 \mathrm{mg} / \mathrm{ml}$, NOVAFARMA). Serially diluted serum was challenged with an equal volume of the RSV-A2 strain, previously tittered to give 150 PFU per $50 \mu \mathrm{l}$ of inoculum. The serum/virus mixtures were incubated at $37^{\circ} \mathrm{C}, 5 \% \mathrm{CO}_{2}$ for $1 \mathrm{~h}$.

96-well plates plated with Vero cell monolayers were infected with $50 \mu \mathrm{l} /$ well (in triplicates) of the serum/virus mixture. Plates were blotted with $0.5 \%$ methyl cellulose, prepared in DMEM with $2 \%$ FBS and incubated at $37^{\circ} \mathrm{C}, 5 \% \mathrm{CO}_{2}$ for 3 days to allow plaque formation. To detect the syncytium formation, wells were incubated with primary anti-RSV antibodies (Millipore) and secondary antibody HRP-Rabbit anti-mouse IgG (Millipore) for 1 hour at $37^{\circ} \mathrm{C}$. Blocking occurred with blotto (5\% milk, $0.05 \%$ tween in PBS $1 \mathrm{X}$ buffer). For revelation, we used 4-chloro-1-napthol with $0.01 \% \mathrm{H}_{2} \mathrm{O}_{2}$ for 20 
min in dark. Syncytium was counted in optical microscope and PFUs calculated by ratio of the number of syncytium by multiplying the dilution with virus medium volume in the plate.

\section{Flow Cytometry}

Splenocytes were labeled with: anti-IL-21R (PE, 4A9 clone) and anti-CD19 (APC-Cy7, ID3 clone) from BD Biosciences, anti-CD4 (eFluor710-PerCP, clone RM4-5), anti-PD1 (PE-Cyanine7, clone J43), anti-Bcl-6 (PE mgl191E clone), anti- CXCR5 (APC, clone SPRCL5), anti-ICOS (FITC, clone 7E17G9), anti-CD45R (FITC, clone RA3-6B2) and anti-CD274 (PE, clone MIH5) from eBioscience, and anti-Ki67 (PE, clone 16A8) from BioLegend. For intracellular staining, we used Foxp3 staining buffer Set (eBioscience) and cells were analyzed using a FACSCanto II (BD Biosciences) with the FACSDiva software (BD Biosciences). Alternatively, for sorter cells were used FASCAria (BD Biosciences).

\section{Histology and Immunohistochemistry}

Lungs and spleens were fixed with $10 \%$ formalin, embedded in paraffin and cut into 5 $\mu \mathrm{m}$-thick sections. Hematoxylin and eosin staining was performed in slide sections to evaluated inflammation scores. For immunohistochemistry, slides sections were deparaffinized with xylol and endogenous peroxidase activity was blocked by incubation with $3 \% \mathrm{H}_{2} \mathrm{O}_{2}$ in methanol. Antigen unmask was performed by incubating the slides in $0.1 \mathrm{~mol} / \mathrm{L}$ citrate buffer, $\mathrm{pH} 6$, for $30 \mathrm{~min}$ at $95^{\circ} \mathrm{C}$, followed by cooling at room temperature for $1 \mathrm{~h}$. Sections were blocked in PBS with $4 \%$ bovine serum albumin (BSA), 5\% mouse serum, and incubated with primary antibody anti-PD-L1 (clone MIH5, eBioscience) at 1:1000 dilution in PBS, 1\% BSA, and 1.25\% mouse serum. 
Biotinylated goat-derived secondary antibodies were detected by the avidin-biotinhorseradish peroxidase complex method (Dako Systems) using 3,3-diaminobenzidinetetrahydrochloride (Sigma-Aldrich) as a substrate.

\section{Real Time-PCR}

Total RNA was extracted from the lungs of infected animals using Viral RNA/DNA Mini Kit (PureLink® - Invitrogen) following manufacturer's instructions. CDNA was synthesized with random primers using Sensiscript $\AA^{\circledR}$ Reverse Transcription kit (QIAGEN®). The quality of cDNA for each sample was tested by amplification of the endogenous $\beta$-actin gene using specific primers from TaqMan Assay (Applied Biosystems). Samples that did not amplify for $\beta$-actin were excluded. Real-time PCR was performed for the amplification of the RSV F protein gene using the primers and specific probes (forward-5'-AACAGATGTAAGCAGCTCCGTTATC-3 ', reverse-5'GATTTTTATTGGATGCTGTACATTT-3 'and probe 5'-FAM / TGCCATAGCATGACACAATGGCTCCT-TAMRA / -3'). For standard curve a ten-fold serial dilutions of $6 \times 10^{7}$ copies of a plasmid with RSV F protein sequence were added to the same plate of $\mathrm{qPCR}$ in duplicate. The results were measured by StepOne ${ }^{\mathrm{TM}}$ Real-Time PCR System (Applied Biosystems) and used for further quantification of the samples viral load.

\section{Passive immunization}

Mice were separated into 3 groups, the first group received naive $\lg G$ serum, the second group received IgG serum from RSV-infected mouse and the latter group received IgG serum from RSV-infected and IL-21 treated mouse. For IgG purification was used Protein A-Sepharose column (Sigma) following manufacturer's instructions. Each mouse received intraperitoneal $300 \mu \mathrm{g}$ of purified lgG. After two days, animals 
were infected with $10^{7}$ PFU of RSV. Mice were euthanized at day 5 post-infection and lungs were harvesedt for further analysis.

\section{Statistical analysis}

The significance for differences between the groups was analyzed with one-way ANOVA test followed by a Bonferroni post-test or t-test were applied to parametric data using GraphPad Prism software (San Diego, CA, USA). Values demonstrated in graphs are mean and standard deviation (S.D.) and a level of significance of $p<0.05$ was established for the analyses. 


\section{RESULTS}

\section{RSV induces TFH proliferation in vitro.}

Given the importance of TFH cells in helping B cells to produce antibodies, we analyzed whether RSV could modulate TFH cells proliferation in vitro. Mice splenocytes were infected with $10^{2} \mathrm{PFU} / \mathrm{ml}$ of HSV-1 or RSV for 4 days. HSV-1 was used as a positive control since it induces high levels of high affinity HSV-specific antibodies (27-29). We found that both RSV and HSV-1 increase the frequency of TFH $\left(\mathrm{CD}^{+}{ }^{+} \mathrm{CD} 4^{+} \mathrm{CXCR}^{+} \mathrm{PD}-1^{+}\right)$cells compared to uninfected controls (Fig. 1, A and B). TFH cells induced by RSV also expressed ICOS and Bcl6 (Fig. 1 C, supplementary figure 1). RSV-induced TFH cells were proliferating (as seen by Ki67 expression) compared to non-TFH (CD3 $\left.{ }^{+} \mathrm{CD}^{+}{ }^{+} \mathrm{CXCR} 5^{-} \mathrm{PD}-1^{-}\right)$cells (Fig. 1, D and E).

\section{RSV decreases IL-21 secretion and IL-21R expression by TFH and B cells}

We next investigated whether RSV could affect the function of TFH cells. Production of IL-21 is an important indicator of TFH activity (30). IL-21 is necessary for antibody affinity maturation and $B$ cell differentiation, and is known to upregulate the expression of its receptor on CD4+ ${ }^{+}$T cells. No IL-21 production was detected when RSV was added to splenocyte cultures, in contrast to what was observed for HSV-1 (Fig. 2 A). In vivo, IL-21 serum levels were undetectable even 4 days post-infection (Fig. 2 B), again contrasting to the abundant IL-21 induction observed during HSV-1 infection. In vitro, $R S V$ also reduced IL-21R expression on TFH cells (Fig. 2, C and D) and B cells $\left(\right.$ CD3-CD19 $^{+}$) (Fig. 2, E and F), while HSV-1 increased IL-21R expression on these cell populations (Fig. 2 C-F), suggesting the regulation of the IL-21/IL-21R axis was specific to RSV. These data indicate that RSV could negatively modulate the function of TFH 
cells by downregulation of IL-21R expression, as well as of IL-21 production.

\section{IL-21 treatment increases B cell follicle size, IgG production, antibody avidity and neutralization capacity}

We hypothesized that the low levels of IL-21 observed upon RSV infection (Fig. 2 B) would lead to decreased humoral responses against the virus. IL-21 is a key cytokine for humoral immune responses, however the influence of this cytokine in GC reaction and antibody avidity during RSV infection was so far unexplored. To evaluate the IL21 action in RSV infection in vivo, we infected mice with RSV and treated them with recombinant, endotoxin-free IL-21 (Supplementary figure 2). Accordingly, we observed that animals infected with RSV showed undeveloped B cell follicles in the spleen (Fig. $3 \mathrm{~A})$, differently from HSV-1 infected mice, which presented greatly augmented follicles compared to uninfected controls. This was reversed by IL-21 treatment. Exogenous IL21 led to increase in sizes of splenic B cell follicles during RSV infection (Fig. 3 A) as well as increased frequencies of B and TFH cells (Fig 3B and C). Finally, treatment with IL-21 also improved titers (Fig. 3 D), avidity (Fig. 3 E), and neutralization capacity (Fig. $3 \mathrm{~F}$ ) of anti-F protein specific antibodies.

\section{IL-21 treatment protects RSV infected animals and decreases lung inflammation by specific humoral immune response}

To evaluate the protective roles of IL-21 in vivo, similar experimental design was performed (Supplementary figure 2). While pulmonary injury was observed in lungs from untreated RSV-infected mice, (Fig. 4 A, arrows show cell infiltration and reduction of bronchi lumen space), treatment with $\mathrm{IL}-21$ reduced inflammation as well as improved survival compared to untreated infected mice, reducing weight loss in 
infected animals (Fig. 4 B and C). IL-21 treatment also decreases numbers of RSV copies in lungs in RSV-infected mice (Fig. 4 D). These results suggest that IL-21 is essential for protection from RSV infection by activating TFH and B cells function.

To further investigate the immunologic mechanisms of protection, we pretreated (two days before RSV infection) mice i.p. with $300 \mu \mathrm{g}$ of purified IgG from naïve serum and RSV-infected mice serum, either treated or not with IL-21. The results, depicted in Fig.

$4 \mathrm{E}$, indicate that protection can be mediated by IgG alone elicited by IL-21 treatment in infected mice. Thus, low production of IL-21 during RSV infection affect GC reactions, dramatically impairing the generation of a protective, anti-RSV humoral response.

\section{PD-L1 blockade recovers IL-21R expression on TFH and B cells and increases}

\section{IL-21 secretion by TFH cells}

We next investigated possible mechanisms involved in the RSV-induced downregulation of IL-21 levels. Previous studies demonstrated that RSV can upregulate PD-L1 expression on DCs (31). This leads to a decrease in humoral responses, affecting TFH viability (32). Both DCs (CD3-CD11 ${ }^{+}$) and B cells from RSVexposed splenocytes were found to display upregulation of PD-L1 (Supplementary Fig. 3). To determine if RSV could directly induce PD-L1 upregulation in either of these cell populations, we sorted DCs and B cells, and infect them in vitro with RSV. Only DCs upregulated PD-L1 expression as a direct effect of RSV, and DCs also presented higher PD-L1 expression compared to B cells (Fig. 5 A and B). In vivo, RSV infection also led to upregulation of PD-L1 expression, confirmed by immunohistochemistry of infected mice spleens on day 21 post-infection (Fig. $5 \mathrm{C}$ ). These results led us to 
hypothesize that the reduction of IL-21 levels could be linked to the induction of PD-L1 in DCs following RSV infection

The prediction from our hypothesis was that PD-L1 blockade could recover the ability of TFH cells to produce IL-21 in the presence of RSV. To test that, we blocked PD-L1 in vitro, and infected mouse splenocytes with $10^{2} \mathrm{PFU} / \mathrm{ml}$ of RSV for 4 days. Blocking PD-L1 increased IL-21 production by RSV-infected cells, as measured by ELISA (Fig. 5 D). Two days post-infection, IL-21 levels began to decrease in supernatants. At $96 \mathrm{~h}$ post-infection, PD-L1 blockade significantly restored IL-21 secretion (Fig. 5 D). In sorted cells, PD-L1 blockade also recovered IL-21R expression on B cells (Fig. 5 E), however only when B cells were co-cultured with TFH cells and DCs. TFH cells also recovered IL-21R expression upon PD-L1 blockade (Fig. 5 F), demonstrating that reduction of IL-21R expression is linked to PD-L1 function in a DC-dependent manner. These data suggest that engagement of the PD-L1 pathway by RSV impairs TFH secretion of IL-21. This in turn leads to downmodulation of IL-21R expression, both in TFH cells and B cells, contributing to impaired RSV-specific humoral responses (Graphical abstract). 


\section{DISCUSSION}

In this study, we reveal a mechanism by which RSV can evade effector immune responses, interfering with $\mathrm{TFH}$ cells function, and consequently impairing the generation of protective antibodies.

Recent studies report that impairing TFH differentiation and/or function is an important virulence mechanism for different viruses. Lymphocytic choriomeningitis virus (LCMV) negatively modulates antibody responses by killing TFH cells via NK cells cytotoxicity (34). HIV infection induces TFH cells proliferation, however recruits these cells to work as a subclinical virus reservoir during antiretroviral therapy (ART) (35). In addition, HIV infection is associated with decrease of $T$ follicular regulatory cells (TFR) function, leading to TFH cells proliferation and increase of viral replication (36). This might be one of the reasons why HIV humoral immune responses are generally non-protective. Progressive $\mathrm{CD}^{+} \mathrm{T}$ cell loss, non-TFH, is a hallmark of chronic HIV infection, with a subsequent B cell dysfunction and poor antibody responses to vaccines (37). In RSV infections, neutralizing antibodies are formed in upper respiratory tract, however the relative contribution of anti-RSV humoral responses is still controversial. Employing several immunological in vivo and in vitro experimental models, we provide evidence that RSV inhibits TFH cells function, resulting in impaired protection.

RSV induced TFH cells proliferation, and that observation alone could indicate that RSV infection would not affect these cells. However, proliferation by itself cannot be considered as a synonym for function. IL-21 is an important indicator of TFH activity, and while IL-21 production was clearly affected by RSV infection, this was not true for HSV-1, indicating these two viruses employ different strategies regarding TFH cells. 
Previous studies reported modulation of IL-21 expression as a strategy employed by pathogens to evade effector immune responses. For example, serum IL-21 levels and the frequency of IL-21-producing TFH cells in blood was lower in HCV patients compared to healthy individuals (38). Lower frequencies of IL-21-producing CD4 ${ }^{+} \mathrm{T}$ cells also is associated with reduced proliferation and increased expression of the inhibitory receptors like CTLA-4, Tim-3 and PD-1 on HCV-specific CD8 ${ }^{+} \mathrm{T}$ cells in a viral persistence state (39). In fact, IL-21 performs potent and specific effects on mucosal antiviral responses, assisting viral clearance and regulating pulmonary $\mathrm{T}$ and B cell responses (40). IL-21 treatment has been tested against several types of viral pathogens (HBV $(41), \operatorname{HCV}(39), \operatorname{HIV}(42,43))$. Our results demonstrated that treatment of RSV-infected mice with recombinant IL-21 had a protective effect in lung inflammation, reducing weight loss and mortality. They also corroborate results from Dodd et al, in which they demonstrated that IL-21 depletion during priming exacerbates immunopathology after RSV challenge and reduces antibody production, showing the importance of IL-21 in RSV infection (44). Studies in humans suggest that RSV can modulate IL-21 secretion. In a cohort study that characterized the primary and secondary cytokine response to RSV infection, IL-21 was not detected in swab nasal secretion samples from infants recruited during two consecutive winters (45). Our data indicated that treatment with IL-21 successfully enhanced humoral responses to RSV, leading to increases in B cell follicles, anti-F (fusion RSV protein) IgG titers, antibody avidity and neutralization capacity. High-avidity anti-RSV IgG antibodies have been shown to confer protection in infants under 3 months old (9). We observed that the antibodies generated upon IL-21 treatment in infected mice were highly protective upon transfer to naïve animals that were challenged in vivo by RSV. Our data agrees with reports that IL-21 is most important at the beginning of a humoral response, 
activating AID (Activation-induced cytidine deaminase), promoting immunoglobulin switch class and somatic hypermutation.

In addition, IL-21 increases germinal center reactions and induces IL-21R expression on activated $B$ cells and TFH cells (46-48). IL-21R is required to generate TFH cells, GC reaction, B cells, plasma cells and plasmablasts in mice (49). We observed that IL21R was downregulated on TFH and B cells in RSV-infected splenocytes in vitro, consistently with the impairment of IL-21 production. In humans, IL-21 or IL-21R defects cause severe primary immunodeficiency, reduced NK, T and B cell activity and leading to multiple infections (50). Our results indicate that downregulation of IL-21R is another important mechanism associated with the impairment of B cell responses against $R S V$ in mice, evidencing the relevance of the IL-21/IL-21R axis in the generation of protection to this virus.

Finally, we found that decreased IL-21 production during RSV infection is dependent on PD-L1 induction. TFH cells naturally express PD-1 (17), and PD-L1, one of the classic PD-1 ligands, is responsible for immune response homeostasis, negatively modulating PD-1-expressing $T$ cells (51). PD-1-PD-L1 interactions reduce Akt phosphorylation in PD-1 expressing cells, leading to decreases in function and cell survival (52). PD-L1 has been previously reported to be increased in DCs $(31,53)$ and B cells (54) of mice infected with RSV. HSV-1 infection is known to induce protective specific antibodies (55), differently from RSV, suggesting that the induction of PD-L1 by RSV is one of the mechanisms associated with deficient antibody production in RSV infection. In our hands, RSV, but not HSV could directly upregulate PD-L1 expression in DCs; B cells upregulation of PD-L1 needed DCs and T cells. It is possible that the 
mechanism by which PD-1/PD-L1 interactions inhibit TFH cells function is by downregulation of c-Maf expression, a transcriptional factor involved in transactivation of both the promoter and enhancer of the IL-21 gene (56). Transcriptional levels of cMaf are increased upon tolerizing immunotherapy (57) correlating with increased PDL1 levels. Accordingly, Cubas et al demonstrated that HIV infection increased PD-L1 frequency in GC B cells leading to reduction of TFH cells proliferation and IL-21 production (58). Accordingly, several studies have suggested that blockade of PD-1 or PD-L1 may lead to a reversion of T cell dysfunction in the context of chronic infection (59). PD-L1 blockade in regulatory B cells can recover TH1 cell activity in visceral leishmaniasis in a canine model (60). When we blocked PD-L1 in vitro during RSV infection, IL-21 secretion was increased. Our results agree with Zhou et al who observed that IL-21 serum levels were inversely correlated with the high intensity of tumor PD-L1 expression in patients with hepatocarcinoma (61). A previous study demonstrated that PD-L1 expression on lung DCs controls inflammation, and anti-PDL1 treatment of RSV-infected animals induced pro-inflammatory cytokines, exacerbating pulmonary inflammation and host disease (54). In that study, they found only a moderate enhancement of TFH cells numbers, and no improvement of antibody responses, at day 6 after infection (54). However, we found a significant increase in serum RSV-specific antibodies at day 14 post-infection in mice treated with IL-21, but not at day 6 as described by Yao et al. Thus, we believe that the benefit of anti-PD-L1 treatment on RSV antibody response could be overridden by the lung inflammation it would induce - and an early course of II-21 therapy might constitute an interesting approach to circumvent the TFH cell function impairment that ensues upon RSV infection. 


\section{ACKNOWLEDGEMENTS}

This study was supported by grants from Conselho Nacional de Desenvolvimento

Científico e Tecnológico (CNPq), Fundação de Pesquisa do Estado do Rio Grande do

Sul (FAPERGS), Coordenação de Aperfeiçoamento de Pessoal de Ensino Superior (CAPES) and Pontifícia Universidade Católica do Rio Grande do Sul.

\section{DISCLOSURE}

The authors declare no conflict of interest. 


\section{REFERENCES}

1. Hall CB, Weinberg GA, Poehling KA, Erdman D, Grijalva CG, Zhu Y. The Burden of Respiratory Syncytial Virus Infection in Young Children. 2009;

2. Díez-Domingo J, Pérez-Yarza EG, Melero JA, Sánchez-Luna M, Aguilar MD, Blasco AJ, et al. Social, economic, and health impact of the respiratory syncytial virus: a systematic search. BMC Infect Dis [Internet]. 2014;14:544.

3. Anderson LJ, Dormitzer PR, Nokes DJ, Rappuoli R, Roca A, Graham BS. Strategic priorities for respiratory syncytial virus (RSV) vaccine development. Vaccine. 2013;31(SUPPL2).

4. DeVincenzo JP, Wilkinson T, Vaishnaw A, Cehelsky J, Meyers R, Nochur S, et al. Viral load drives disease in humans experimentally infected with respiratory syncytial virus. Am J Respir Crit Care Med. 2010;182(10):1305-14.

5. Hall CB, Walsh EE, Long CE, Schnabel KC. Immunity to and frequency of reinfection with respiratory syncytial virus. J Infect Dis. 1991;163(4):693-8.

6. Falsey AR, Walsh EE. Relationship of serum antibody to risk of respiratory syncytial virus infection in elderly adults. J Infect Dis. 1998;177(2):463-6.

7. Piedra P. Correlates of immunity to respiratory syncytial virus (RSV) associated-hospitalization: establishment of minimum protective threshold levels of serum neutralizing antibodies. Vaccine [Internet]. $2003 \mathrm{Jul}$ 28;21(24):3479-82.

8. Habibi MS, Jozwik A, Makris S, Dunning J, Paras A, DeVincenzo JP, et al. Impaired antibody-mediated protection and defective iga b-cell memory in experimental infection of adults with respiratory syncytial virus. Am J Respir Crit Care Med. 2015;191(9):1040-9.

9. Freitas GRO, Silva DAO, Yokosawa J, Paula NT, Costa LF, Carneiro BM. Antibody Response and Avidity of Respiratory Syncytial Virus-Specific Total IgG , IgG1, and IgG3 in Young Children. 2011;1833(April):1826-33.

10. Sande CJ, Mutunga MN, Okiro EA, Medley GF, Cane PA, Nokes DJ. Kinetics of the Neutralizing Antibody Response to Respiratory Syncytial Virus Infections in a Birth Cohort. J Med Virol [Internet]. 2013 Nov;85(11):2020-5.

11. Falsey AR, Singh HK, Walsh EE. Serum antibody decay in adults following natural respiratory syncytial virus infection. J Med Virol [Internet]. 2006 Nov;78(11):1493-7.

12. Jr JC. Respiratory syncytial virus vaccine development. Vaccine [Internet]. 2001;10(10):1415-33. Available from: http://www.sciencedirect.com/science/article/pii/S0264410X01002870

13. Polack FP, Teng MN, Collins PL, Prince G a, Exner M, Regele H, et al. A role for immune complexes in enhanced respiratory syncytial virus disease. J Exp Med. 2002;196(6):859-65.

14. Killikelly AM, Kanekiyo M, Graham BS. Pre-fusion F is absent on the surface of formalin-inactivated respiratory syncytial virus. Sci Rep [Internet]. 2016;6(September):34108.

15. Liang B, Surman S, Amaro-Carambot E, Kabatova B, Mackow N, Lingemann $\mathrm{M}$, et al. Enhanced Neutralizing Antibody Response Induced by Respiratory 
Syncytial Virus Prefusion F Protein Expressed by a Vaccine Candidate. J Virol [Internet]. 2015;89(18):9499-510.

16. Delgado MF, Coviello S, Monsalvo a C, Melendi G a, Hernandez JZ, Batalle JP, et al. Lack of antibody affinity maturation due to poor Toll-like receptor stimulation leads to enhanced respiratory syncytial virus disease. Nat Med [Internet]. 2009 Jan [cited 2015 May 6];15(1):34-41.

17. Crotty S. Follicular helper CD4 T cells (TFH). Annu Rev Immunol [Internet]. 2011 Jan [cited 2014 Jul 9];29(December):621-63.

18. Weber JP, Fuhrmann F, Feist RK, Lahmann A, Al Baz MS, Gentz L-J, et al. ICOS maintains the $T$ follicular helper cell phenotype by down-regulating Krüppel-like factor 2. J Exp Med [Internet]. 2015 Feb 9 [cited 2015 Jul 17];212(2):217-33.

19. Bentebibel S-E, Schmitt N, Banchereau J, Ueno H. Human tonsil B-cell lymphoma 6 (BCL6)-expressing CD4+ T-cell subset specialized for B-cell help outside germinal centers. Proc Natl Acad Sci U S A [Internet]. 2011 Aug 16 [cited 2015 Jul 31];108(33):E488-97.

20. Cells CT, Kim BCH, Rott LS, Clark-lewis I, Campbell DJ, Wu L, et al. Subspecialization of CXCR5 2 T Cells : B Helper Activity Is Focused in a Germinal Center - localized Subset of. 2001;193(12).

21. Breitfeld BD, Ohl L, Kremmer E, Ellwart J, Sallusto F, Lipp M, et al. Follicular B Helper T Cells Express CXC Chemokine Receptor 5 , Localize to B Cell Follicles, and Support Immunoglobulin Production. 2000;192(11).

22. Linterman M a, Beaton L, Yu D, Ramiscal RR, Srivastava M, Hogan JJ, et al. IL-21 acts directly on B cells to regulate Bcl-6 expression and germinal center responses. J Exp Med [Internet]. 2010 Feb 15 [cited 2015 Nov 4];207(2):35363.

23. Chan TD, Brink R. Affinity-based selection and the germinal center response. Immunol Rev. 2012;247(1):11-23.

24. Victora GD, Nussenzweig MC. Germinal centers. Annu Rev Immunol [Internet]. 2012;30:429-57.

25. Linterman MA, Hill DL. Can follicular helper T cells be targeted to improve vaccine efficacy? F1000Research [Internet]. 2016;5(May).

26. Zielinska E, Liu D, Wu H-Y, Quiroz J, Rappaport R, Yang D-P. Development of an improved microneutralization assay for respiratory syncytial virus by automated plaque counting using imaging analysis. Virol J [Internet]. 2005;2:84.

27. Whitley RJ, Roizman B. Herpes simplex virus infections. 2001;357:1513-8.

28. Mancuso R, Baglio F, Agostini S, Cabinio M, Lagan?? MM, Hernis A, et al. Relationship between herpes simplex virus-1-specific antibody titers and cortical brain damage in Alzheimer's disease and amnestic mild cognitive impairment. Front Aging Neurosci. 2014;6(OCT):1-8.

29. Gutierrez J, Rodriguez M, Maroto MC, Piedrola G, Peiron J. Behaviour of IgG antibody avidity for the antigen and of IgA antibody in active cytomegalovirus, Epstein-Barr virus, herpes simplex virus and human herpes virus 6 infections. Adaptation of a commercial test. J Infect. 1997;35(1):25-30. 
30. Eto D, Lao C, DiToro D, Barnett B, Escobar TC, Kageyama R, et al. IL-21 and IL-6 are critical for different aspects of B cell immunity and redundantly induce optimal follicular helper CD4 T cell (Tfh) differentiation. PLoS One [Internet]. 2011 Jan [cited 2015 Jun 21];6(3):e17739.

31. Wang $\mathrm{H}$, Peters $\mathrm{N}$, Schwarze J. Plasmacytoid dendritic cells limit viral replication, pulmonary inflammation, and airway hyperresponsiveness in respiratory syncytial virus infection. J Immunol [Internet]. 2006;177(9):6263-70.

32. Hams E, McCarron MJ, Amu S, Yagita H, Azuma M, Chen L, et al. Blockade of B7-H1 (programmed death ligand 1) enhances humoral immunity by positively regulating the generation of T follicular helper cells. J Immunol [Internet]. 2011 May 15 [cited 2015 Jun 1];186(10):5648-55.

33. Crotty S. T Follicular Helper Cell Differentiation, Function, and Roles in Disease. Immunity [Internet]. 2014 Oct [cited 2014 Oct 16];41(4):529-42.

34. Cook KD, Kline HC, Whitmire JK. NK cells inhibit humoral immunity by reducing the abundance of $\mathrm{CD} 4+\mathrm{T}$ follicular helper cells during a chronic virus infection. J Leukoc Biol [Internet]. 2015 May 18 [cited 2015 Jul 17];98(October).

35. Miles B, Connick E. TFH in HIV Latency and as Sources of ReplicationCompetent Virus. Trends Microbiol [Internet]. 2016;24(5):338-44.

36. Chowdhury A, Del Rio PME, Tharp GK, Trible RP, Amara RR, Chahroudi A, et al. Decreased T Follicular Regulatory Cell/T Follicular Helper Cell (TFH) in Simian Immunodeficiency Virus-Infected Rhesus Macaques May Contribute to Accumulation of TFH in Chronic Infection. J Immunol [Internet]. 2015;195:3237-47.

37. Pallikkuth S, Parmigiani A, Silva SY, George VK, Fischl M, Pahwa R, et al. Impaired peripheral blood T-follicular helper cell function in HIV-infected nonresponders to the $2009 \mathrm{H} 1 \mathrm{N1}$ / 09 vaccine. 2016;120(5):985-94.

38. Spaan M, Kreefft K, de Graav GN, Brouwer WP, de Knegt RJ, ten Kate FJW, et al. CD4+ CXCR5+ T cells in chronic HCV infection produce less IL-21, yet are efficient at supporting B cell responses. J Hepatol [Internet]. 2015 Feb [cited 2015 Jul 17];62(2):303-10.

39. Kared H, Fabre T, B??dard N, Bruneau J, Shoukry NH. Galectin-9 and IL-21 Mediate Cross-regulation between Th17 and Treg Cells during Acute Hepatitis C. PLoS Pathog. 2013;9(6).

40. Spolski R, Leonard WJ. Interleukin-21: a double-edged sword with therapeutic potential. Nat Rev Drug Discov [Internet]. 2014;13(5):379-95.

41. Li L, Liu M, Cheng L-W, Gao X-Y, Fu J-J, Kong G, et al. HBcAg-specific IL-21producing $C D 4+T$ cells are associated with relative viral control in patients with chronic hepatitis B. Scand J Immunol [Internet]. 2013;78(5):439-46.

42. Yue FY, Lo C, Sakhdari A, Lee EY, Kovacs CM, Benko E, et al. HIV-specific IL21 producing CD4+ T cells are induced in acute and chronic progressive HIV infection and are associated with relative viral control. J Immunol. 2010;185(1):498-506.

43. Pallikkuth S, Pahwa S. Interleukin-21 and T follicular helper cells in HIV infection: research focus and future perspectives. Immunol Res [Internet]. 2013 Dec [cited 2015 Jul 15];57(1-3):279-91. 
44. Dodd JS, Clark D, Muir R, Korpis C, Openshaw PJM. Endogenous IL-21 regulates pathogenic mucosal CD4 T-cell responses during enhanced RSV disease in mice. Mucosal Immunol [Internet]. 2013 Jul [cited 2015 Jul 17];6(4):704-17.

45. Ugonna K, Douros K, Bingle CD, Everard ML. Cytokine responses in primary and secondary respiratory syncytial virus infections. Pediatr Res [Internet]. 2016; (November 2015).

46. Avery DT, Deenick EK, Ma CS, Suryani S, Simpson N, Chew GY, et al. B cellintrinsic signaling through IL-21 receptor and STAT3 is required for establishing long-lived antibody responses in humans. J Exp Med [Internet]. 2010;207(1):155-71.

47. Nojima T, Haniuda K, Moutai T, Matsudaira M, Mizokawa S, Shiratori I, et al. In-vitro derived germinal centre B cells differentially generate memory B or plasma cells in vivo. Nat Commun [Internet]. 2011;2:465.

48. Caprioli F, Sarra M, Caruso R, Stolfi C, Fina D, Sica G, et al. Autocrine regulation of IL-21 production in human T lymphocytes. J Immunol. 2008;180(3):1800-7.

49. Choi YS, Kageyama R, Eto D, Escobar TC, Johnston RJ, Monticelli L, et al. ICOS receptor instructs $T$ follicular helper cell versus effector cell differentiation via induction of the transcriptional repressor Bcl6. Immunity [Internet]. 2011 Jun 24 [cited 2015 Jul 1];34(6):932-46.

50. Kotlarz D, Ziętara N, Milner JD, Klein C. Human IL-21 and IL-21R deficiencies. Curr Opin Pediatr [Internet]. 2014;26(6):704-12.

51. Wherry EJ. T cell exhaustion. Nat Immunol [Internet]. 2011 Jun [cited 2014 Jul 14];131(6):492-9.

52. Okazaki T, Honjo T. The PD-1-PD-L pathway in immunological tolerance. Trends Immunol. 2006;27(4):195-201.

53. Sow FB, Gallup JM, Krishnan S, Patera AC, Suzich J, Ackermann MR. Respiratory syncytial virus infection is associated with an altered innate immunity and a heightened pro-inflammatory response in the lungs of preterm lambs. Respir Res [Internet]. 2011;12(1):106.

54. Yao S, Jiang L, Moser EK, Jewett LB, Wright J, Du J, et al. Control of pathogenic effector T-cell activities in situ by PD-L1 expression on respiratory inflammatory dendritic cells during respiratory syncytial virus infection. Mucosal Immunol [Internet]. 2015 Jul [cited 2015 Jul 17];8(4):746-59.

55. Chew T, Taylor KE, Mossman KL. Innate and Adaptive Immune Responses to Herpes Simplex Virus. 2009;979-1002.

56. Hiramatsu Y, Suto A, Kashiwakuma D, Kanari H, Kagami S, Ikeda K, et al. cMaf activates the promoter and enhancer of the IL-21 gene, and TGF-beta inhibits c-Maf-induced IL-21 production in CD4+ T cells. J Leukoc Biol. 2010;87(4):703-12.

57. Jogdand GM, Mohanty S, Devadas S. Regulators of Tfh cell differentiation. Front Immunol. 2016;7(NOV):1-14.

58. Cubas R a, Mudd JC, Savoye A-L, Perreau M, van Grevenynghe J, Metcalf T, et al. Inadequate $T$ follicular cell help impairs B cell immunity during HIV 
infection. Nat Med [Internet]. 2013 Apr [cited 2015 Jul 17];19(4):494-9.

59. Dyck L, Mills KHG. Immune checkpoints and their inhibition in cancer and infectious diseases. Eur J Immunol [Internet]. 2017;1-37.

60. Schaut RG, Lamb IM, Toepp AJ, Scott B, Mendes-Aguiar CO, Coutinho JF V., et al. Regulatory IgD hi B Cells Suppress T Cell Function via IL-10 and PD-L1 during Progressive Visceral Leishmaniasis. J Immunol [Internet]. 2016;196(10):4100-9.

61. Zhou Z, Tong D, Guan J, Tan H, Zhao L, Zhu Y, et al. Follicular helper T cell exhaustion induced by PD-L1 expression in hepatocellular carcinoma results in impaired cytokine expression and B cell help, and is associated with advanced tumor stages. 2016;8(7):2926-36. 


\section{FIGURES}

FIGURE 1. RSV induces TFH cell proliferation in vitro. Splenocytes were incubated with ether live RSV or HSV-1, UV inactivated RSV or HSV-1, or Vero cells supernatant for 4 days. (A) Representative and (B) Mean TFH $\left(\mathrm{CD} 3^{+} \mathrm{CD} 4^{+} \mathrm{CXCR} 5^{+} \mathrm{PD}-1^{+}\right)$cells percentages. (C) Bcl-6 and ICOS expression by TFH cells (RSV, black line; HSV-1, black dotted line; negative control, hatched gray histogram). (D) Representative histograms and (E) MFI of Ki67 expression on TFH (Control, gray line; RSV, black dotted line) and non-TFH CD4 ${ }^{+} \mathrm{T}$ cells $\left(\mathrm{CD}^{+} \mathrm{CD} 4^{+} \mathrm{CXCR}\right.$-PD-1-) (Control, hatched gray histogram; RSV, hatched dark gray histogram). Results are the mean of one representative experiment of three performed. ${ }^{*} \mathrm{P}<0.05$; ${ }^{* *} \mathrm{P}<0.01 ;{ }^{* * *} \mathrm{P}<0,001$.

FIGURE 2. RSV infection decreases splenocyte IL-21 secretion as well as IL-21R expression in TFH and B cells. Splenocytes were incubated with ether live RSV or HSV-1, UV inactivated RSV or HSV-1, or Vero cells supernatant) for 4 days. (A) IL-21 in supernatant of cultured infected splenocytes. (B) Serum IL-21 levels in mice (three per group) infected with RSV or HSV-1, measured by ELISA. (C) Representative histogram and (D) MFI of IL-21R expression in TFH cells. (E) Representative histogram and (F) MFI of IL-21R expression in B (CD3-CD19+) cells. (RSV, black line; HSV-1, black dotted line; negative control, hatched gray histogram) Results are the mean of one representative experiment of three performed. ${ }^{*} \mathrm{P}<0.05 ;{ }^{* *} \mathrm{P}<0.01 ;{ }^{* \star *} \mathrm{P}<0,001$.

FIGURE 3. In vivo IL-21 treatment increases B cell follicles size, IgG production, avidity and neutralization capacity. BALB/c mice were infected with $10^{7} \mathrm{PFU}$ of RSV or HSV-1 (intranasally or intraperitoneally, respectively) and treated subcutaneously with 4 doses of $0.5 \mu \mathrm{g}$ of IL-21. (A) Spleen HE histology, 40x magnification. Bar scale: $200 \mu \mathrm{m}$. Quantification of B follicle size, by fold increase. (B) Percentages of B cells. (C) Percentages of TFH cells. (D) Anti-F IgG titers measured by ELISA. (E) Total IgG avidity index on days 18 and 21 after infection. (F) Neutralization capacity assay. Results are the mean of one representative experiment of three performed using three mice per experiment. ${ }^{*} \mathrm{P}<0.05 ;{ }^{* *} \mathrm{P}<0.01 ;{ }^{* \star *} \mathrm{P}<0,001$.

FIGURE 4. In vivo IL-21 treatment protects RSV infected animals and decreases lung inflammation. BALB/C mice were infected with $10^{7} \mathrm{PFU}$ of RSV or HSV-1 (intranasally or intraperitoneally, respectively) and treated subcutaneously with 4 doses of $0.5 \mu \mathrm{g}$ of IL-21. (A) Lung HE histology (100x magnification), 21 days postinfection. Bar scale: $50 \mu \mathrm{m}$. Arrows indicate bronchial constriction and inflammation. (B) Weight loss, plotted over time. (C) Kaplan-Meier survival curves. (D) RT-PCR quantification of RSV copies in lungs, 21 days after infection. (E) Passive immunization with purified IgG from naïve, RSV-infected mice or IL-21 treated RSV-infected mice measured of RSV copies in lungs by RT-PCR. Results are the mean of one representative experiment of three performed using three mice per experiment. ${ }^{*} P$ $<0.05 ;{ }^{* *} \mathrm{P}<0.01 ;{ }^{* \star *} \mathrm{P}<0,001$. 
FIGURE 5. PD-L1 blockade recovers IL-21R expression in TFH and B cells and

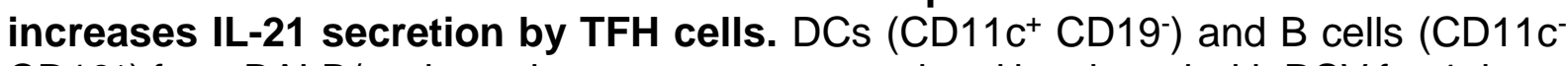
$\mathrm{CD}_{19}$ ) from BALB/c mice splenocytes were sorted and incubated with RSV for 4 days. (A) MFI of PD-L1 in sorter DCs. (B) MFI of PD-L1 in sorter B cells. (C) Spleen PD-L1 immunohistochemistry 21 days after infection (three mice per group) with $10^{7}$ PFUs of RSV, 40x magnification. Bar scale: $200 \mu \mathrm{m}$. Zoom black dotted square: 100x magnification. (D) IL-21 levels in supernatant of infected splenocytes, with or without aPD-L1 treatment. (E) MFI from IL-21R in coculture sorted B cells. (F) MFI from IL$21 \mathrm{R}$ in coculture sorted TFH cells. Results are the mean of one representative experiment of three performed. ${ }^{*} \mathrm{P}<0.05 ;{ }^{* \star} \mathrm{P}<0.01 ;{ }^{* \star *} \mathrm{P}<0,001$.

GRAPHICAL ABSTRACT. RSV infection impairing IL-21 secretion by TFH cells via PD-L1induction in dendritic cells and B cells. Low levels of IL-21 lead to poor RSVspecific humoral immune responses, low antibody titer, avidity and neutralization capacity. PD-L1 blockade can upregulate IL-21 secretion, and IL-21 treatment restores the entire immune humoral responses, resulting in protection against RSV infection. 


\section{FIGURE 1}

A

\section{Gated on $\mathrm{CD}^{+} \mathrm{CD}^{+}$}
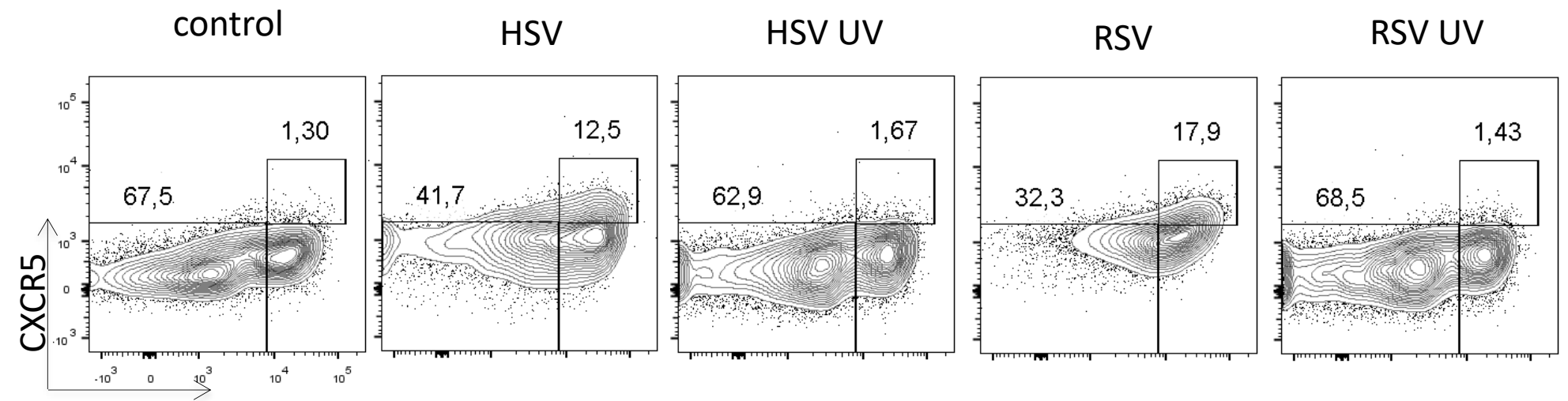

PD-1

B

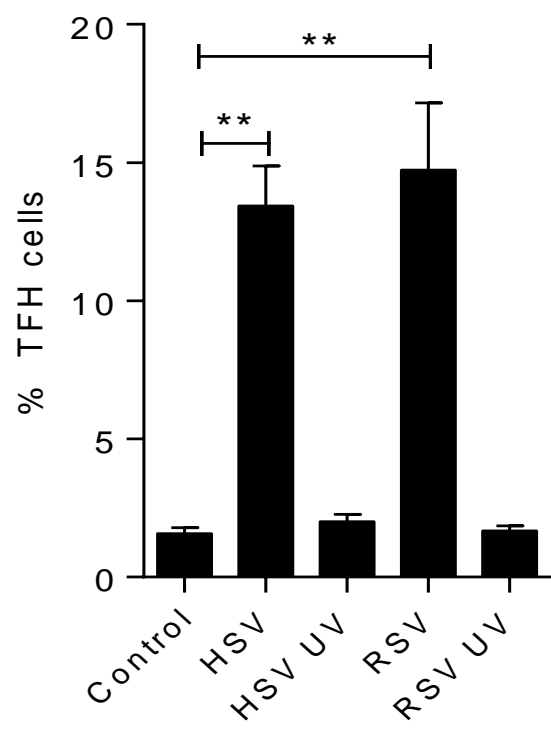

D

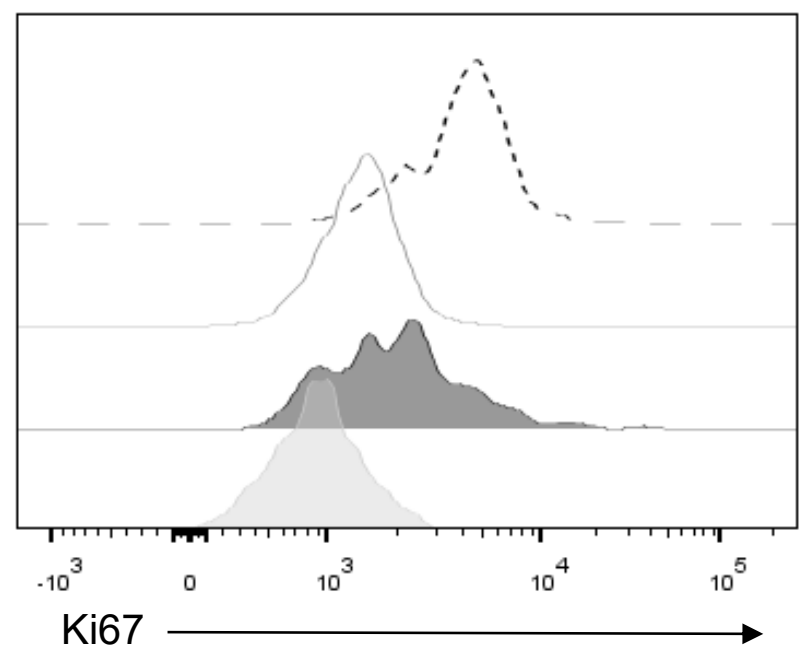

Gated on $\mathrm{CD}^{+} \mathrm{CD} 4^{+} \mathrm{CXCR} 5^{+} \mathrm{PD}-1^{+}$
C

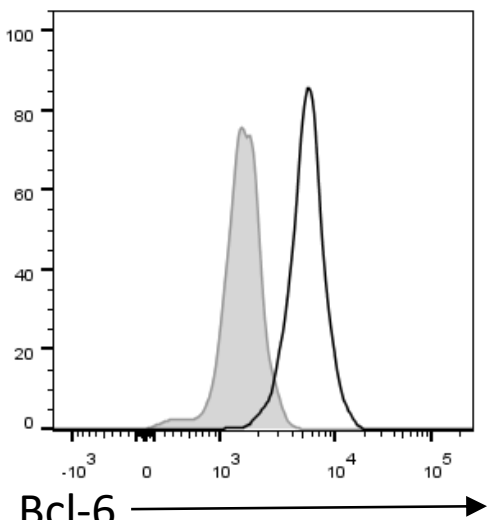

Bcl-6
Control

\section{$\mathbf{E}$}



\section{Control
RSV}

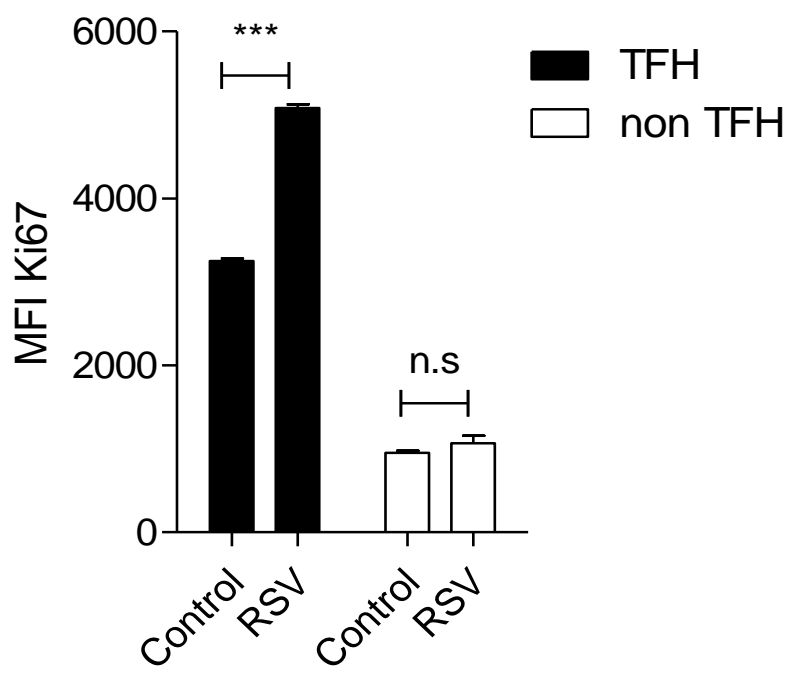




\section{FIGURE 2}

A

B

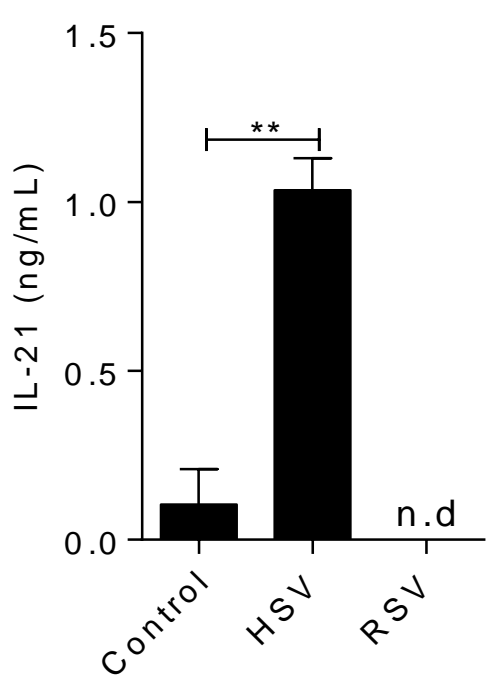

Gated on $\mathrm{CD}^{+} \mathrm{CD}^{+} \mathrm{CXCR5}^{+} \mathrm{PD}-1^{+}$

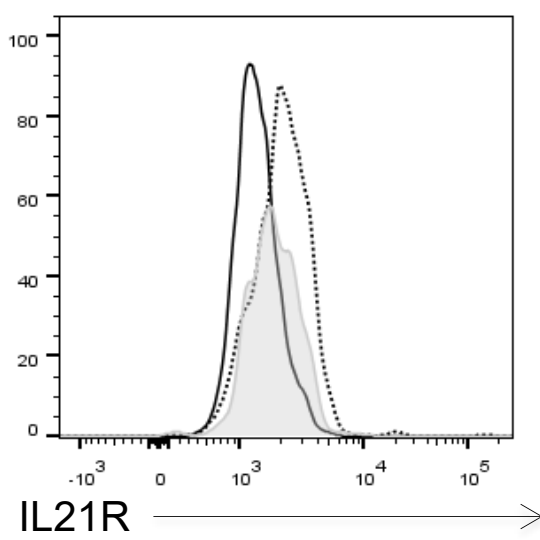

E Gated on $\mathrm{CD}^{-} \mathrm{CD} 19^{+}$

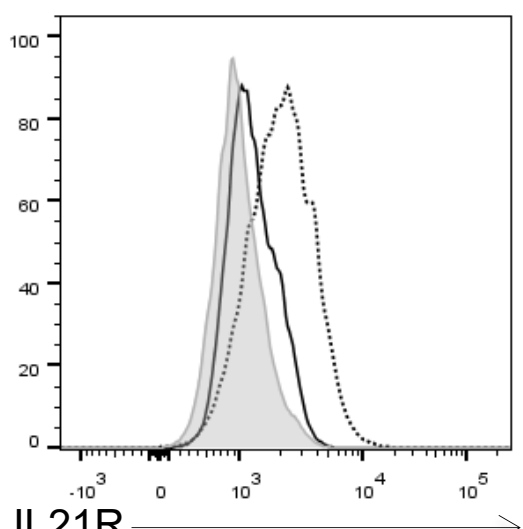

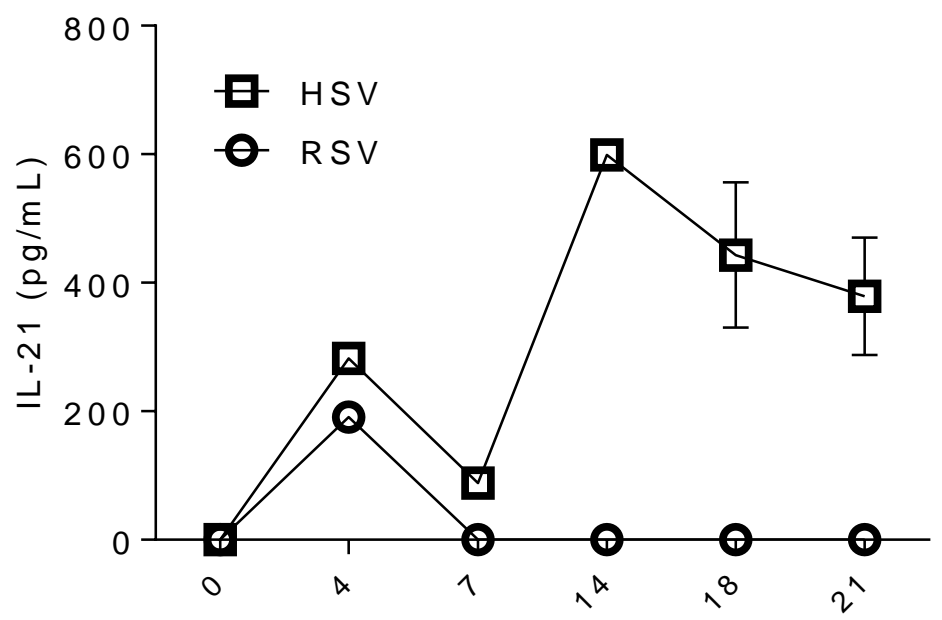

Days post-infection

D

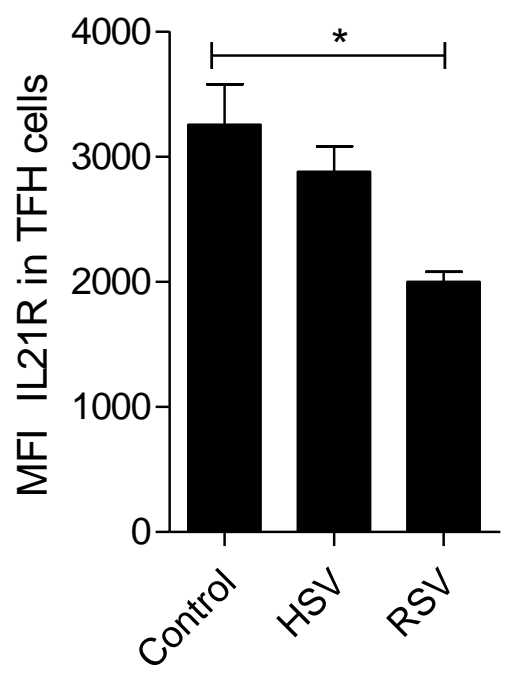

$\mathbf{F}$

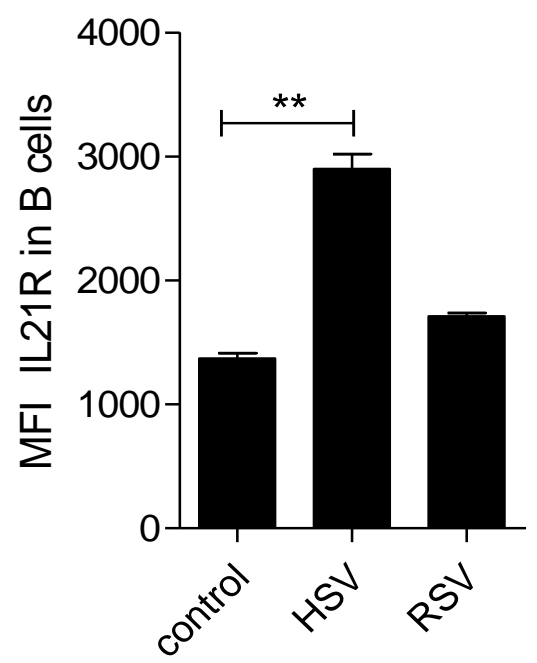




\section{FIGURE 3}

\section{A}
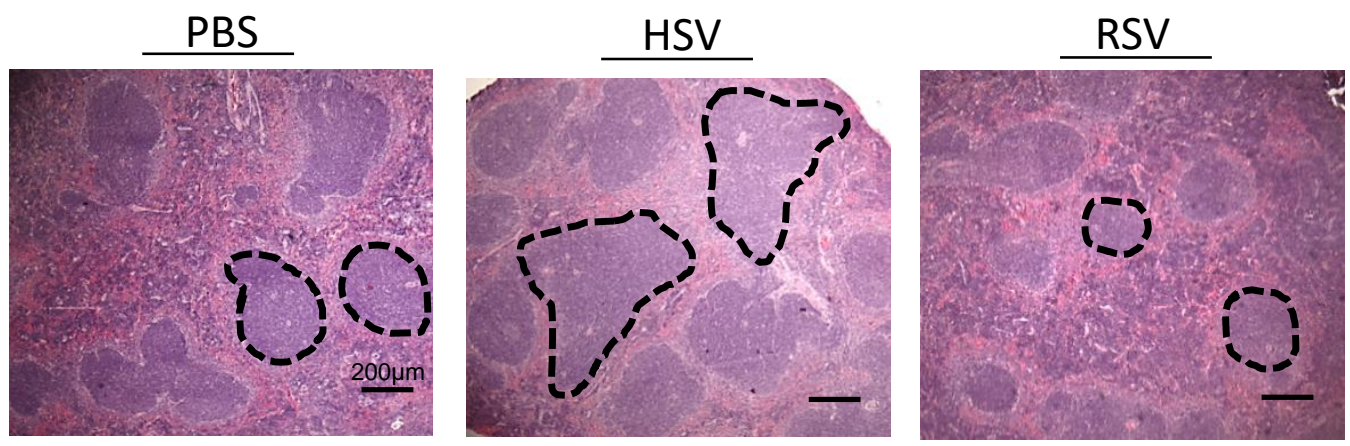

RSV+IL-21

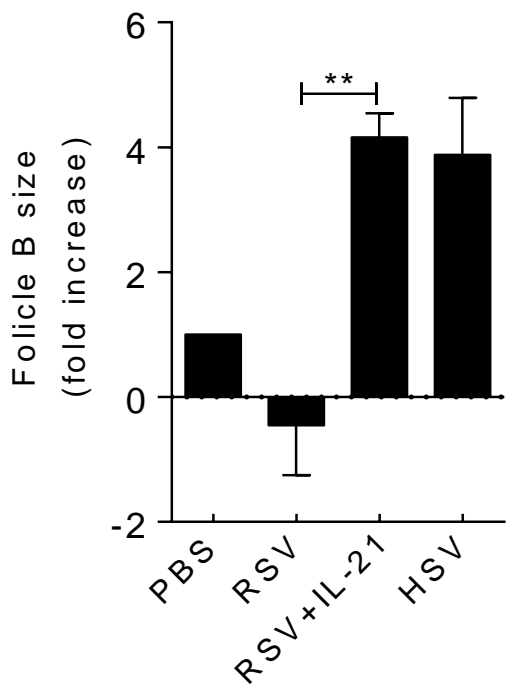

B

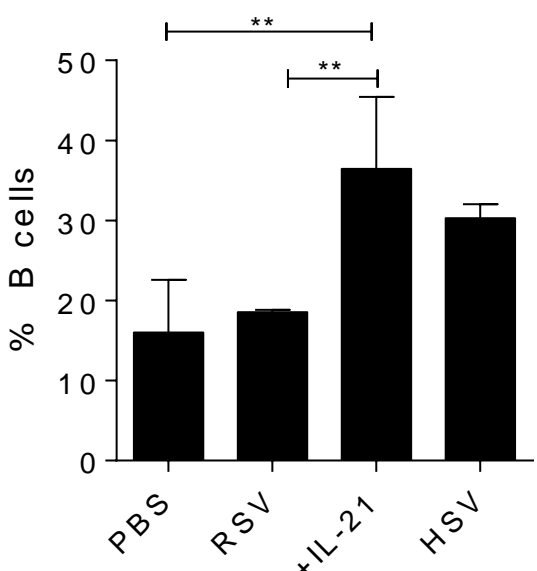

C

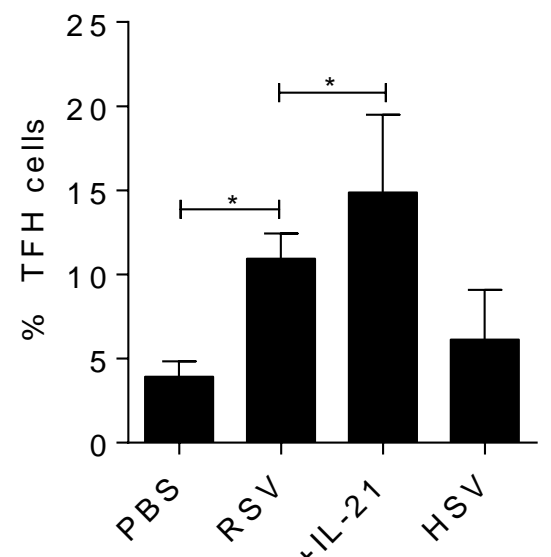

$\mathbf{E}$

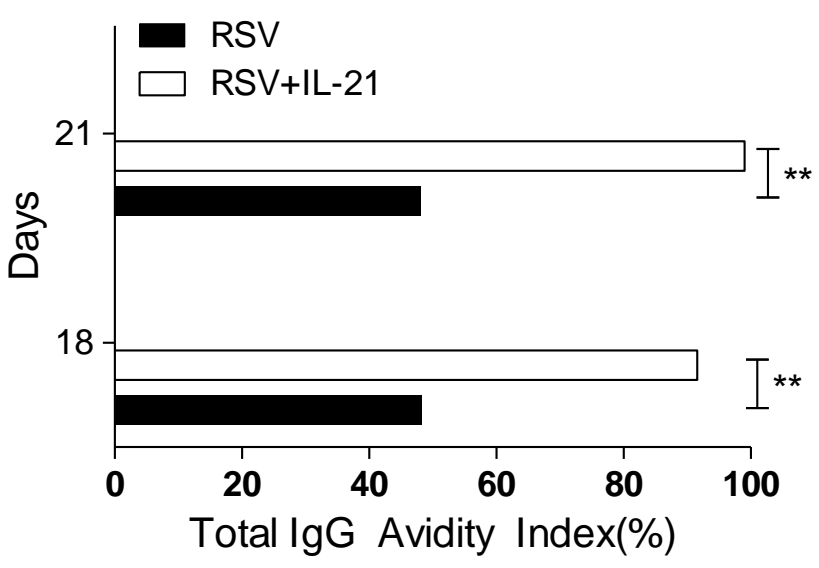

D

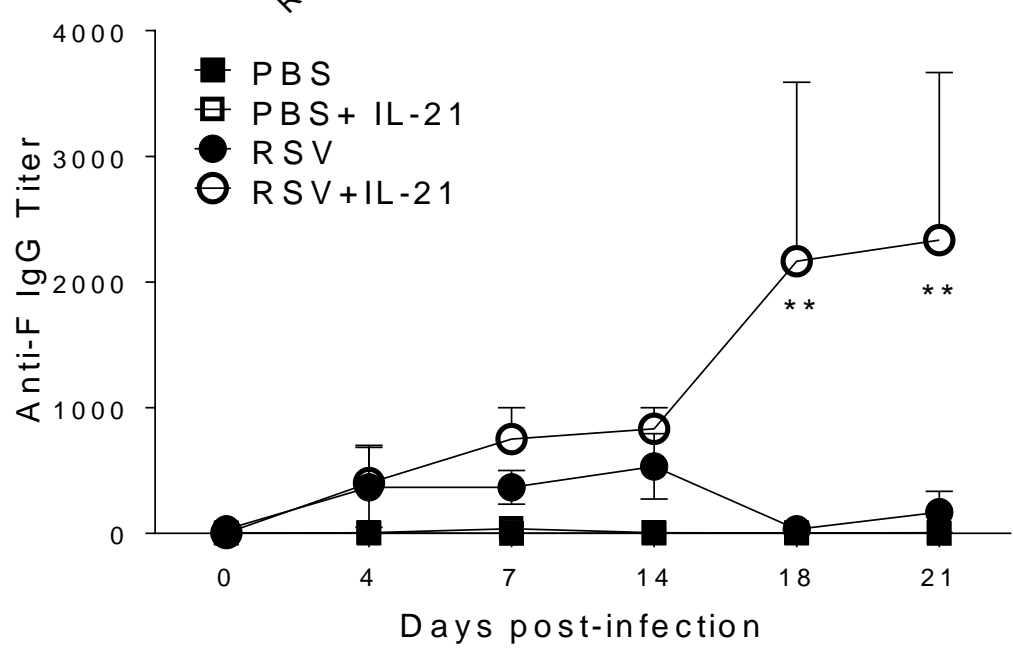

F

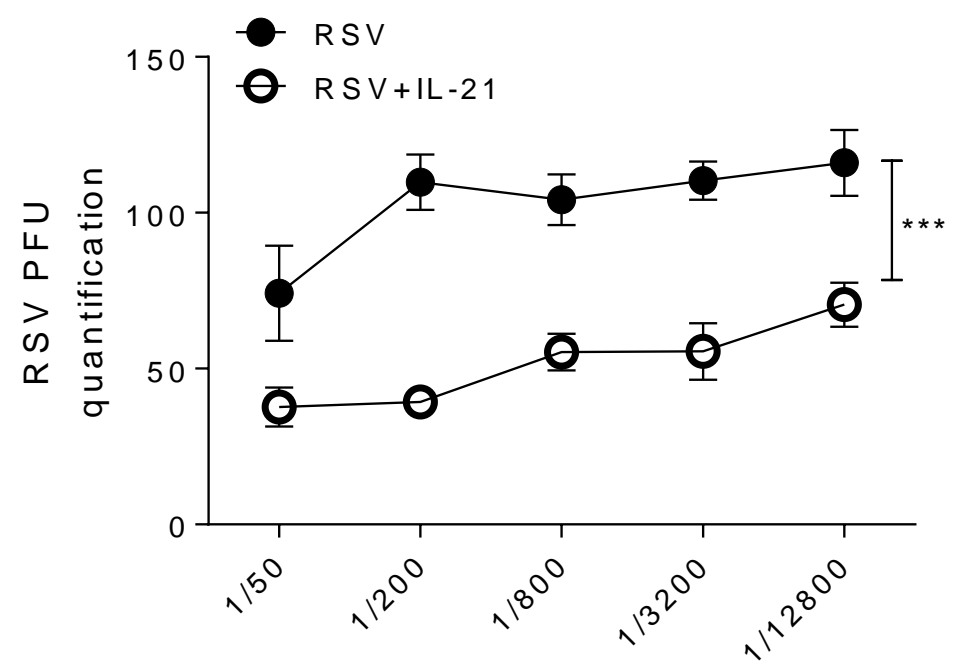




\section{FIGURE 4}

A
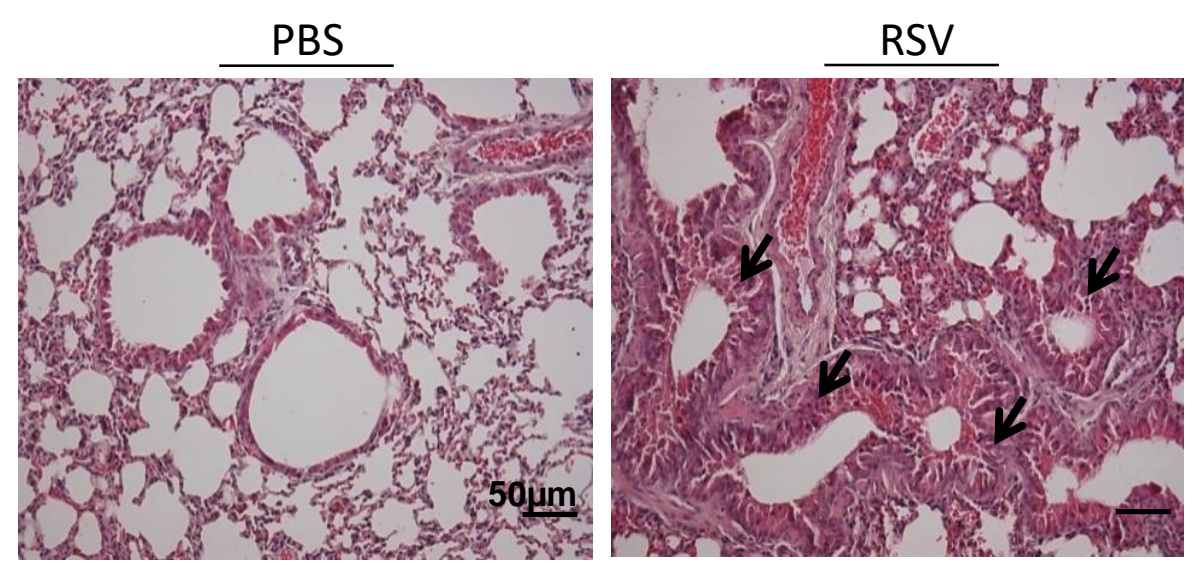

RSV+IL-21

B

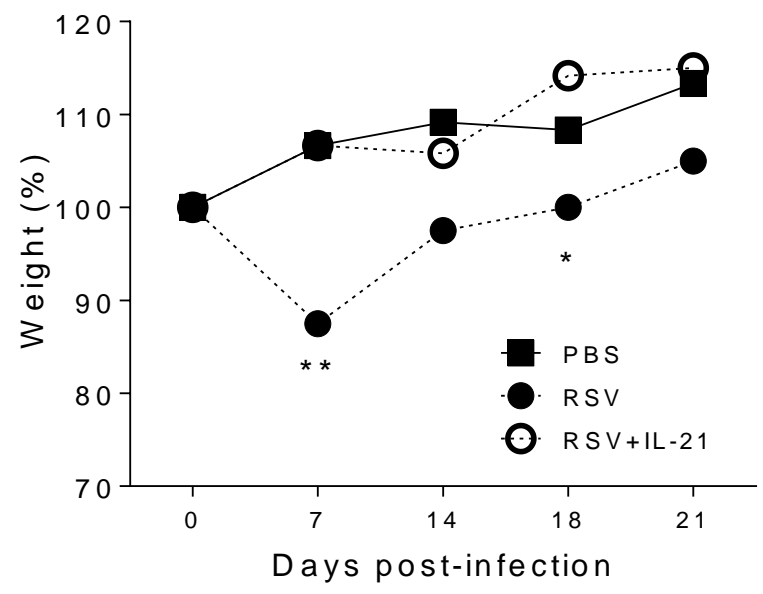

D

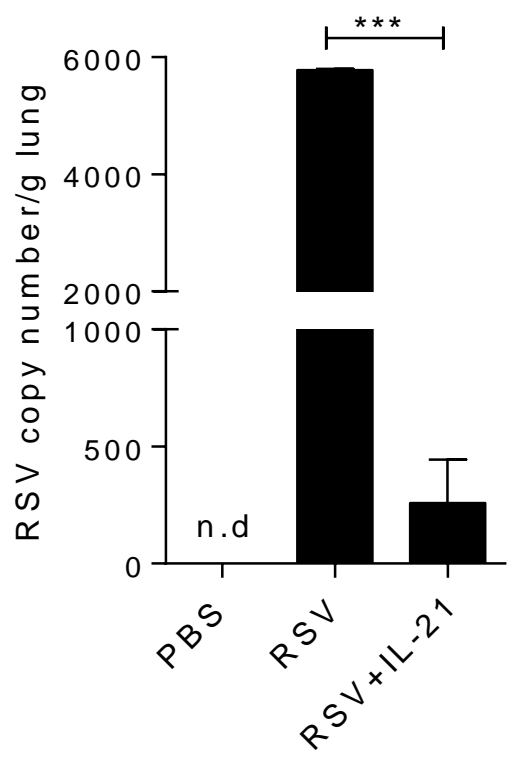

C

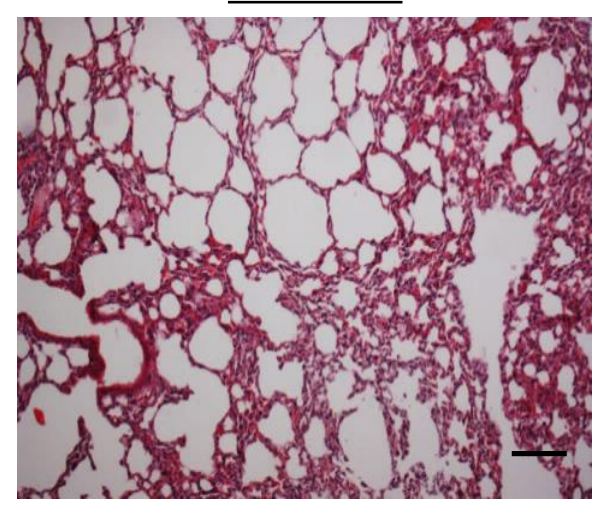

$\mathbf{E}$
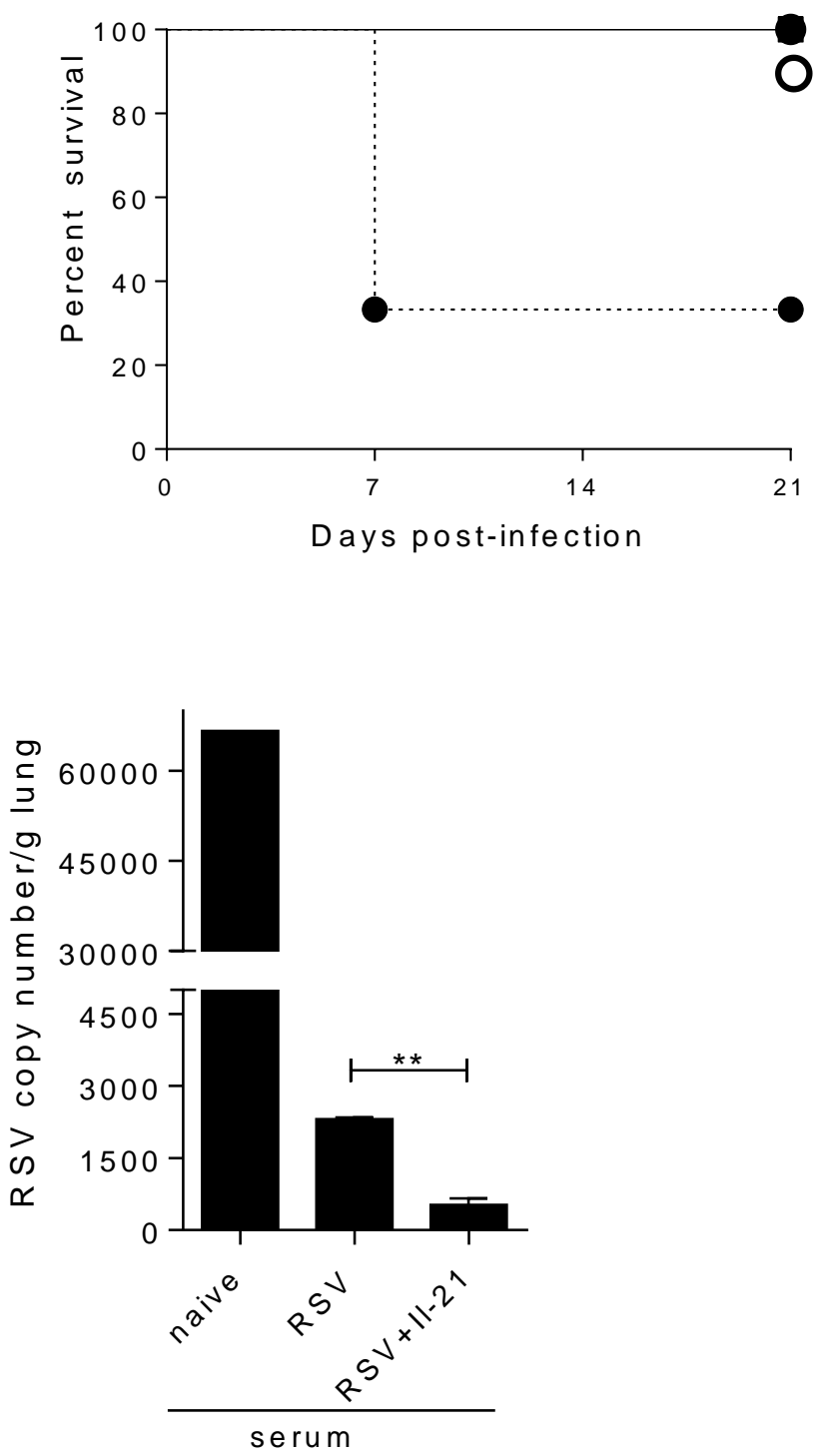
bioRxiv preprint doi: https://doi.org/10.1101/203133; this version posted November 8, 2017. The copyright holder for this preprint (which was not certified by peer review) is the author/funder, who has granted bioRxiv a license to display the preprint in perpetuity. It is made available under aCC-BY 4.0 International license.

\section{FIGURE 5}

A

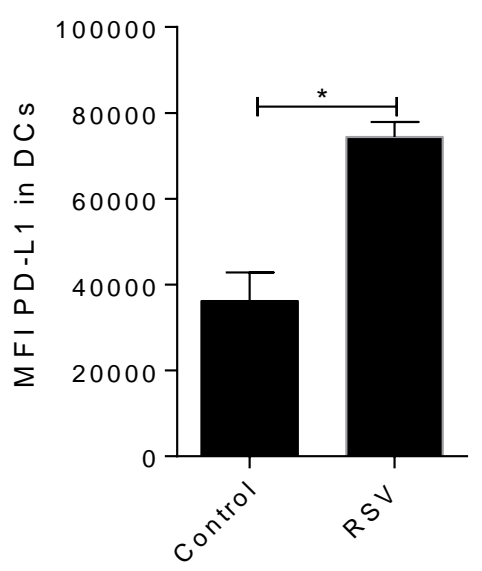

C
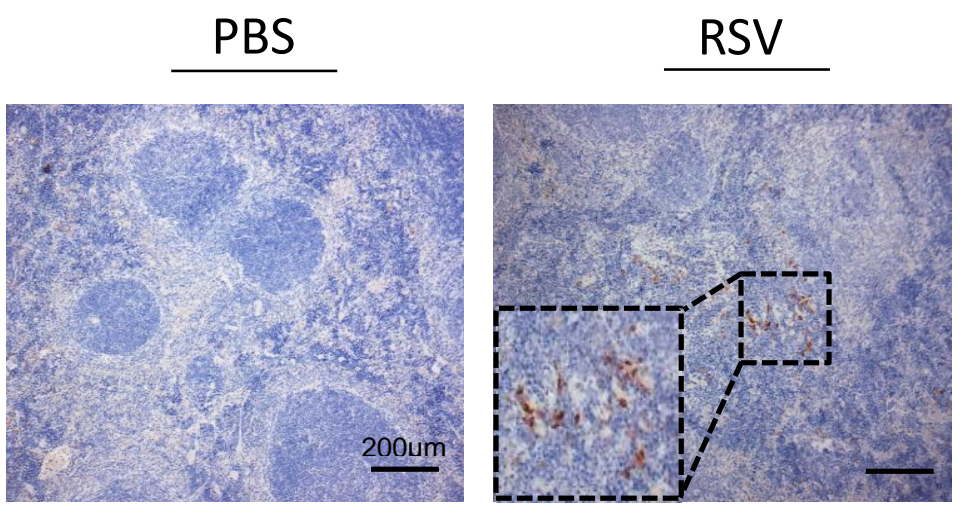

$\mathbf{E}$

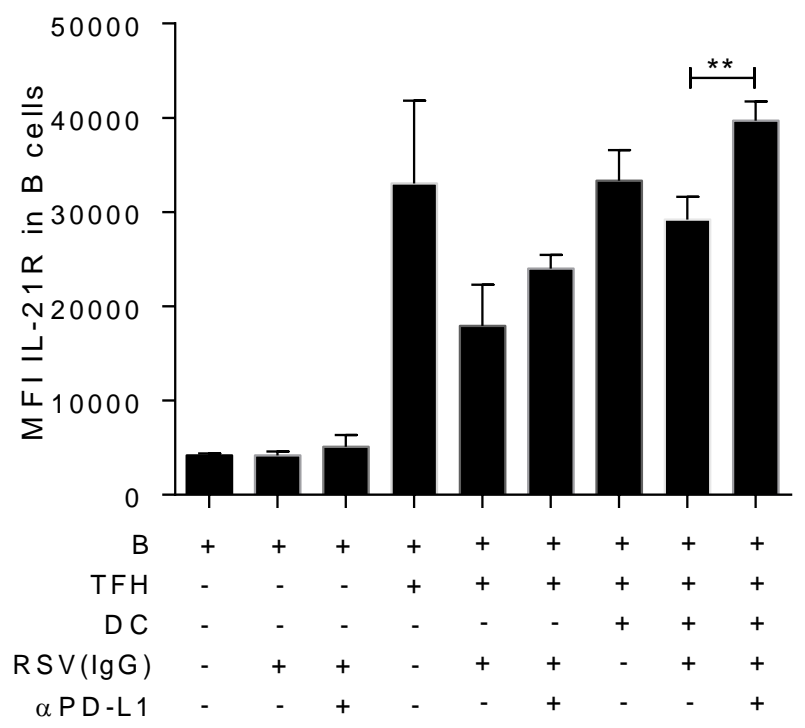

B

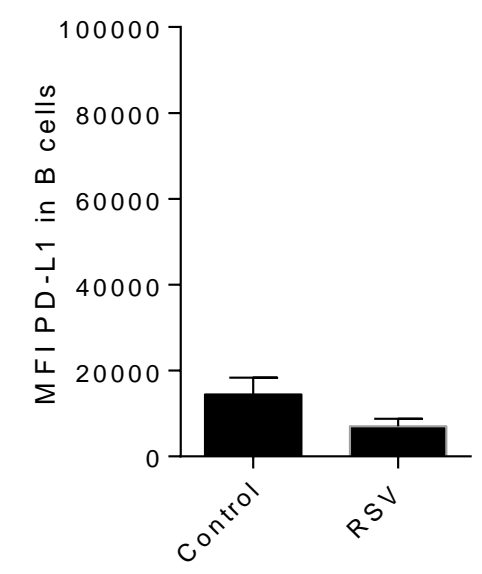

D

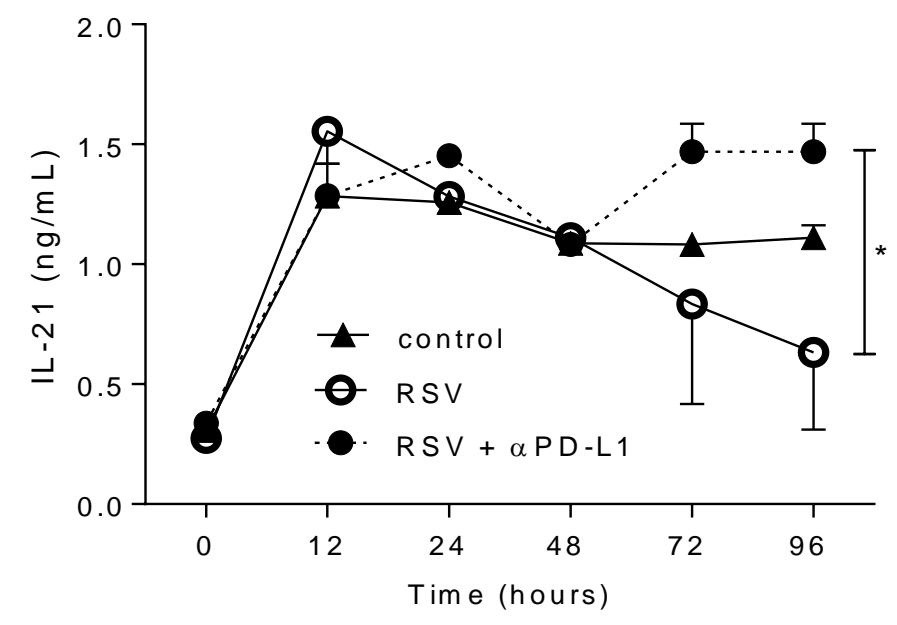

F

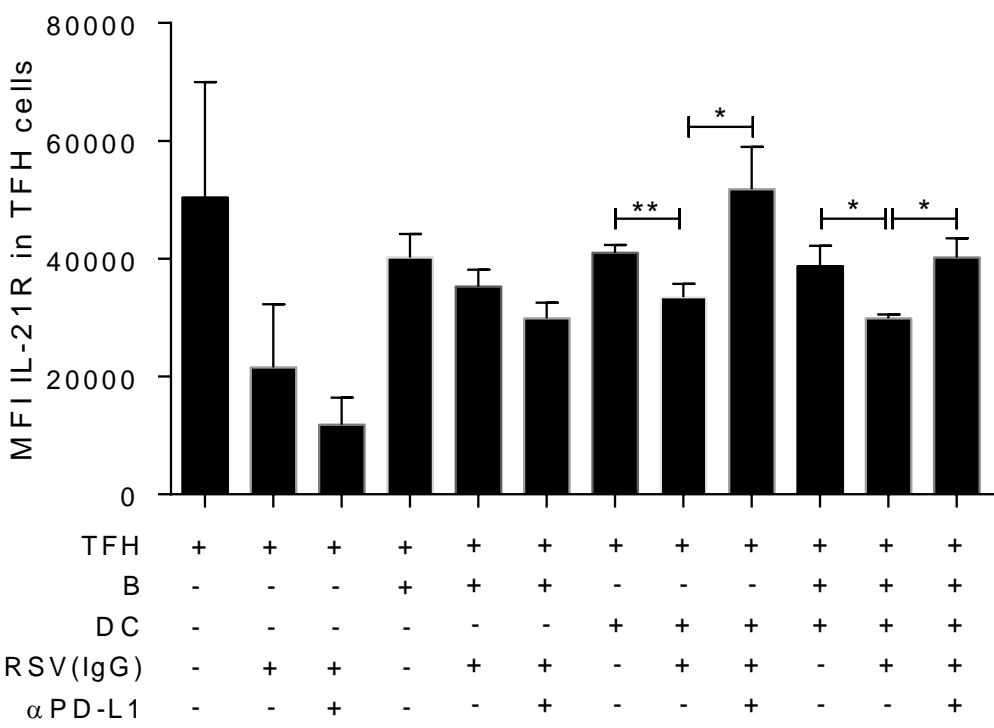




\section{GRAPHICAL ABSTRACT}



